\title{
Curvature distribution within hillslopes and catchments and its effect on the hydrological response
}

\author{
P. W. Bogaart ${ }^{1}$ and P. A. Troch ${ }^{1, *}$ \\ ${ }^{1}$ Hydrology and Quantitative Water Management Group, Wageningen University, The Netherlands \\ *now at: Department of Hydrology and Water Resources, The University of Arizona, Tucson, Arizona, USA
}

Received: 23 March 2006 - Published in Hydrol. Earth Syst. Sci. Discuss.: 20 June 2006

Revised: 2 November 2006 - Accepted: 13 November 2006 - Published: 6 December 2006

\begin{abstract}
Topographic convergence and divergence are first order controls on the hillslope and catchment hydrological response, as evidenced by similarity parameter analyses. Hydrological models often do not take convergence as measured by contour curvature directly into account; instead they use comparable measures like the topographic index, or the hillslope width function. This paper focuses on the question how hillslope width functions and contour curvature are related within the Plynlimon catchments, Wales. It is shown that the total width function of all hillslopes combined suggest that the catchments are divergent in overall shape, which is in contrast to the perception that catchments should be overall convergent. This so-called convergence paradox is explained by the effect of skewed curvature distributions and extreme curvatures near the channel network. The hillslopestorage Bossiness (hsB) model is used to asses the effect of within-hillslope convergence variability on the hydrological response. It is concluded that this effect is small, even when the soil saturation threshold is exceeded. Also described in this paper is a novel algorithm to compute flow path lengths on hillslopes towards the drainage network, using the multidirectional flow redistribution method.
\end{abstract}

\section{Introduction}

The terrestrial part of the hydrological cycle is driven by hydrometeorological fluxes such as rainfall, but controlled by landscape properties. An understanding of these landscape properties is thus a prerequisite for successful rainfall-runoff modelling, especially for applications in ungauged basins.

In this paper we limit ourselves to landscapes that are characterized by the following constrains:

Correspondence to: $\mathrm{P}$. W. Bogaart

(patrick.bogaart@wur.nl)
- The channel network is well-defined and consists of perennial streams only. The channel network is thus fixed in time and space.

- The non-channelized part of the landscape consists of hillslopes that connect topographic divides with the channel network. Every point in the landscape thus drains towards the channel network and "pits" do not occur.

- Hillslopes consists of a highly permeable soil layer overlying an impermeable bedrock. The thickness of the soil layer is small, as compared to the characteristic length.

As a result of these constrains, the hydrology of landscapes considered will be dominated by lateral subsurface flow and saturation-excess overland flow on hillslopes, and open-channel flow within the channel network.

Its is assumed that these conditions hold for the majority of catchments in humid climates. Notably exceptions are sedimentary basins, where groundwater flow will dominate, and semi-arid climates where the channel network extent is highly dynamic, and the dominant runoff generating process will be infiltration-excess.

The mechanisms by which landscape properties control the hydrological response of catchments fall intro three broad, and not completely mutually exclusive, categories:

- Ecological factors, like vegetation type and density, which control processes like rainfall interception, evapotranspiration, and biogenic modification of hydraulic soil properties

- Hydraulic factors, like saturated hydraulic conductivity, water retention characteristics and macropores.

- Geometric factors, like hillslope shape and size, soil depth, and channel network topology.

Published by Copernicus GmbH on behalf of the European Geosciences Union. 
These three categories are not entirely independent, in the sense that e.g. soil hydraulic properties are strongly affected by plant and soil ecology. Also, on a long (longer than a year) time scale, there is a feedback from hillslope hydrology to these controlling factors: vegetation composition is affected by the soil moisture regime, hillslope length is limited by a channelization threshold.

This paper is concerned with the last group of hydrologically relevant landscape characteristics, being hillslope and catchment geomorphology.

The classical form of geomorphic information is a digital elevation model (DEM), and the classical way to use it for hydrological purposes is to build a two or three-dimensional gridded spatially distributed hydrological model, where each grid cell has an associated topographic elevation, and water is allowed to flow from grid cell to grid cell. This can be considered as an explicit way of incorporating geomorphic data. In some sense, because grid cells are only linked through common boundaries, the larger scale spatial correlations and structures that exist in the geomorphic surface are ignored.

There are, however, alternative ways of applying geomorphic data in a more implicit way, that, by doing so, do respect these larger scale geomorphic structures.

An example of a simple model that conforms to this implicit use of geomorphic data is the overland flow and sediment transport model KINEROS (Woolhiser et al., 1990; Smith et al., 1995; Canfield and Goodrich, 2006). In this model, the channel network is broken up into individual channel links, each represented by a "channel" model element having a single, characteristic length, cross-sectional geometry, and slope. The hillslopes are broken up into individual 'plane' model elements, each having a characteristic width, length, and slope.

The model thus starts from some observations regarding the regularity that is present within catchments: channel links can be adequately described by straight lines, and hillslope elements by rectangular planes. Higher order geomorphic attributes such as stream profile concavity and hillslope curvature are thus regarded as second-order with respect to their effect on hydrology and sediment transfer.

Parametrization of the KINEROS model requires the identification and delineation of landscape elements as channels and hillslopes, which by definition requires the interpretation of individual DEM grid cells in a spatial and geomorphic context.

A second, more advanced example of the implicit use of topographic information for hydrological purpose is the TOPMODEL (Beven and Kirkby, 1979; Beven, 1997; Kirkby, 1997). The basic idea is that under hydraulic steady state, local (perched) groundwater level is directly related to the so-called topographic index $\lambda$

$\lambda=\log A_{c} / \tan \alpha$

where $A_{c}[\mathrm{~L}]$ is the upstream contributing area, per unit contour line width, and $\tan \alpha$ is the local topographic slope gra- dient. The topographic index $\lambda$ thus describes the balance between the amount of water that has to pass through a given point (proportional to $A_{c}$ ), and the gravity-controlled subsurface flow velocity (proportional to $\tan \alpha$ ). In effect, the index $\lambda$ functions as a similarity index, because all point of equal $\lambda$ are assumed to behave similar, despite differences in $A_{c}$ and $\tan \alpha$. The TOPMODEL then routes water not through a (two-dimensional) spatial grid, but instead through a (onedimensional) histogram of $\lambda$. Much of the topographic structure of hillslopes has thus been captured in this histogram. Sivapalan et al. (1990) explored the possibility of approximating the shape of the $\lambda$ histogram with a 3-parameter gamma distribution, reducing the amount of required topographic data even further.

The idea of developing similarity indices for hydrological applications has been extensively explored by Aryal et al. (2002) who derived such indices from topographic, soil, and climatic attributes. the extent of hillslope saturation was found to be defined by three parameters:

- An input index that relates water supply $q$ to the soil transmissivity and the first-order hillslope geometry (length, slope). This index, which is derived in a similar fashion as TOPMODEL's $\lambda$, predicts occurrence and extent of saturated areas on planar hillslopes.

- Two parameters describing the second-order hillslope geometry, i.e. planform and profile curvature. These parameters modify the predictions made by the input parameter.

In a later paper, this theory is extended to the prediction of response time after a change in water balance (Aryal et al., 2005).

All examples described above use some simplifying assumptions regarding the flow process, being either in steady state, or approximated by the kinematic wave theory, and thus ignoring diffusive hydraulic processes. Recently, Berne et al. (2005), starting from a linearized version of the hillslope-storage Boussinesq model (Troch et al., 2003), derived a similarity parameter that described the balance between diffusive and advective subsurface flow components: the hillslope Péclet number, defined by

$$
P e=\frac{L \tan \alpha}{2 p D}-\frac{a L}{2}
$$

where $L$ hillslope length, $p$ a linearization parameter, $D$ soil depth (the product $p D$ is equivalent to a characteristic average perched groundwater height), and $a$ a planform curvature measure. Berne et al. (2005) proceed further by showing that a unique relationship exists between $P e$ and the moments of the characteristic response function (i.e. the recession hydrograph). Thus, $P e$ can be regarded as a similarity parameter.

Summarizing, the question how the characteristic hydrological response within a catchment varies (e.g. as measured 
by the moments) can thus be reduced to the question how similarity indices like $\lambda$ and $P e$ vary within the landscape.

In an ideal case, a catchment can be subdivided into a (fixed) drainage network and a (fixed) hillslope that folds around the channel network. This hillslope should then be broken up into geometrically homogeneous individual hillslopes, each characterized by a set of morphometric parameters $L, D, \alpha, a$.

It appears that of all morphometric parameters discussed, the first order parameters (length, slope) are relatively easily observed, measured and understood, while this is more problematic for second-order parameters such as convergence/divergence. Therefore, after a brief discussion of controls on $L, D, \alpha$, this paper's focus will be on flow line convergence and divergence, which is an important parameter in all hydrogeomorphic similarity indices described above.

\section{Morphometric parameters}

\subsection{Hillslope gradient}

Hillslope gradient $\tan \alpha$ is primarily controlled by the tectonic and geomorphological setting of the hillslope and catchment. For low-relief areas, where tectonic uplift rate is slow, diffusive geomorphic processes will prevail. The resulting morphology consists of dome-shaped hills, with wide flat tops, slowly steepening towards the channel network. The classic model to describe this process is the linear geomorphic diffusion law, given by

$q_{s}=k_{D} \tan \alpha$

where $k_{D}\left[\mathrm{~L}^{2} \mathrm{~T}^{-1}\right]$ is a diffusivity constant, and $q_{s}\left[\mathrm{~L}^{2} \mathrm{~T}^{-1}\right]$ the volumetric sediment transport per unit hillslope width. A typical order-of-magnitude value for $k_{D}$ is $0.01 \mathrm{~m}^{2} / \mathrm{yr}$ (Rosenbloom and Anderson, 1994). For landscapes where topography is in approximately steady state, material removed from hillslopes by surface erosion is equal to material inserted from below by uplift. For a unit width hillslope strip of length $L$, this latter volume is equal to

$q_{s}=U L$

where $U\left[\mathrm{~L} \mathrm{~T}^{-1}\right]$ is the tectonic uplift rate. Equating Eqs. (3) and (4) and solving for $L$ yields

$\tan \alpha=U L / k_{D}$.

The interpretation of Eq. (5) conforms to common sense knowledge of hillslopes: hillslopes get steeper if they are longer; they get steeper if tectonic action is stronger; they get steeper if erodibility is lower.

There is however a strong constraint on maximum values of $\alpha$. Landsliding and other mass wasting processes will limit slope angles. The effect of these processes is that $\alpha \leq \alpha_{c}$, where $\alpha_{c}$ is a "critical" slope angle, that is controlled by soil material, cohesion, pore pressures etc. Note that the latter

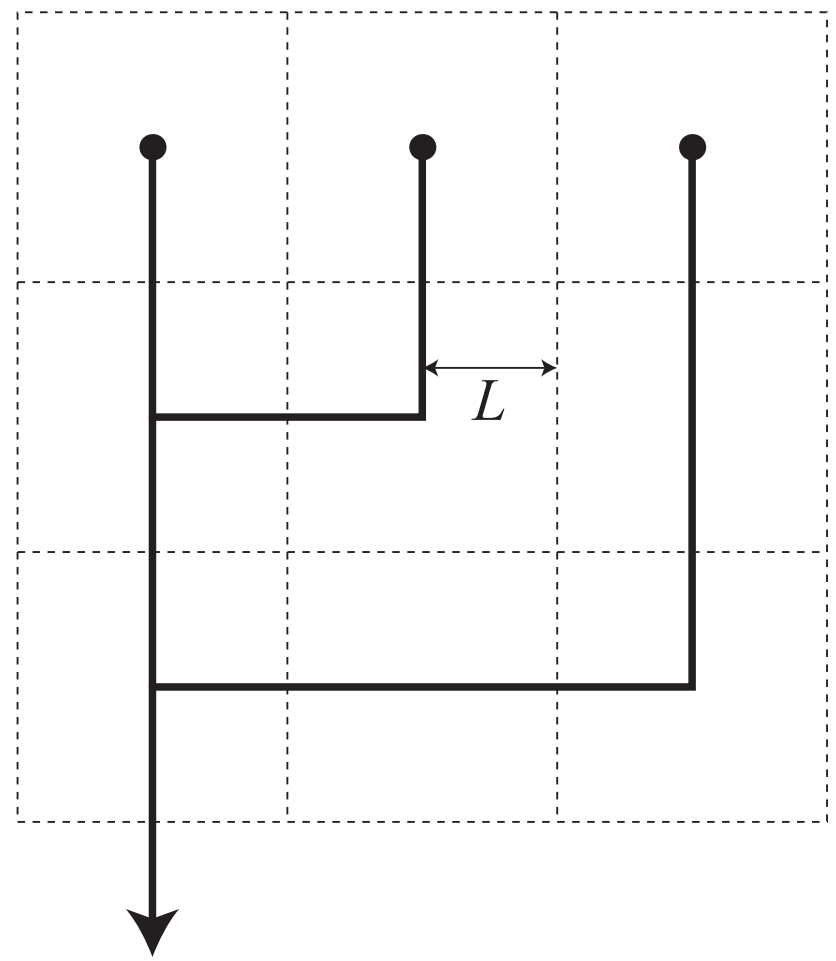

Fig. 1. Cartoon illustrating the relationship between hillslope length and drainage density. A tile with an area of $A=4 L^{2}$ has a channel length of (averaged over all tiles) $\approx 2 L$, resulting in a drainage density of $L / 2$

implies strong feedbacks between hillslope hydrology and morphology, at least on longer time scales. A typical value for the critical slope angle is $\tan \alpha_{c} \approx 0.3$

There is growing evidence that many diffusional processes do behave more non-linear than previously assumed (Roering et al., 1999; Martin, 2000). Corresponding models suggest a continuous transition between linear diffusion at small slope angles, towards landsliding-like strongly nonlinear transport at high slope angles.

\subsection{Hillslope length}

Hillslope length is directly related to drainage density (the total length of stream channels per catchment area). For a highly idealized "random-walk" catchment, as shown in Fig. 1, one can show that

$L \approx 1 / 2 D_{d}$

where $L[\mathrm{~L}]$ is hillslope length and $D_{d}\left[\mathrm{~L}^{-1}\right]$ drainage density.

Drainage density is defined by the location of channel heads, or "sources". Channel heads are primarily a geomorphic feature but have a clear hydrologic significance, because they demarcate the subsurface flow dominated hillslopes from surface flow dominated channels. Different explanations for channel head locations have been proposed, 
reasoning onwards from hydro-geomorphic or hydrologic controls.

The classical hydro-geomorphic model for channel head locations is based on a stability analysis for geomorphic hillslope evolution (Smith and Bretherton, 1972; Tarboton et al., 1992; Smith et al., 1997): infinitesimally small hollows on a hillslope will act as a focal point for water and sediment transported from upslope, due to flowline convergence just upflow of the hollow. If the (increased) amount of sediment delivered to the hollow is larger than the (increased) sediment transport capacity from the hollow downwards, the hollow will tend to fill up and disappear. If, on the other hand, the delivered amount is smaller than the local transport capacity, the hollow will grow and channelization will initiate.

So, the channel network extent, and thus characteristic hillslope length, is primarily controlled by sediment transport, which is in itself strongly dependent on hillslope hydrology. As a general rule, "dry" sediment transport (such as most mass wasting processes) lead to stable, unchannelled hillslopes, while "wet" sediment transport (due to overland flow) leads to instabilities and hence channelization.

Thus, in general, the hillslope-channel transition will coincide with the transition from subsurface-dominated to surface-dominated hydrology. This observation is the starting point for an analysis that yields the maximum area of unchannelled zero-order drainage basins (O'Loughlin, 1986; Tucker and Bras, 1998). It is assumed that in many cases the (shallow, perched) groundwater flow can be satisfactory described by a kinematic wave approach, and that the head gradient (that is the physical basis for flow) can be approximated by the topographic slope gradient (that can be easily derived from terrain information) (Troch et al., 2002). Then, for a given basin of area $A$, bottom width $w$ and characteristic effective precipitation rate $P$, the steady state water flux through the lower boundary will be $A P / w$. The subsurface flow capacity, however, is the product of soil transmissivity $T$ and local slope gradient $\alpha$. Overland flow and hence channelization will occur when $A P / w>T \alpha$.

\subsection{Profile curvature}

Profile curvature $c_{p}\left[\mathrm{~L}^{-1}\right]$ measures the topographic curvature along a flow line, i.e. a steepest descent path. It is computed by (Mitasova and Hoffierka, 1993; Schmidt et al., 2003)

$c_{p}=\frac{f_{x x} f_{x}^{2}+2 f_{x y} f_{x} f_{y}+f_{y y} f_{y}^{2}}{\left(f_{x}^{2}+f_{y}^{2}\right)\left(f_{x}^{2}+f_{y}^{2}+1\right)^{3 / 2}}$

where $f_{x}$ etc. are the first and second order partial derivatives of the topographic surface $z=f(x, y)$. See Schmidt et al. (2003) for a discussion on methods to compute these from a raster DEM. Positive (negative) $c_{p}$ indicate concave (convex) profiles.
The variability of profile curvature within hillslopes and catchments is directly related to the governing geomorphic processes. Landscapes where diffusional erosion dominates will have domed-shaped hills with flat tops and steeper slope bases, but convex in overall shape.

\subsection{Contour curvature}

Contour curvature (sometimes named "planform curvature") $c_{c}\left[\mathrm{~L}^{-1}\right]$ measures the curvature of contour lines on topographic maps. It it directly related to the convergence and divergence of flow lines, which are by definition perpendicular to the contour lines. It is computed by (Mitasova and Hoffierka, 1993; Schmidt et al., 2003)

$c_{c}=\frac{f_{x x} f_{y}^{2}-2 f_{x y} f_{x} f_{y}+f_{y y} f_{x}^{2}}{\left(f_{x}^{2}+f_{y}^{2}\right)^{3 / 2}}$

(Note that the corresponding equation in Table 1 of Schmidt et al. (2003) contains a typo: the first $f_{x}$ should be an $f_{y}$ ). Positive (negative) $c_{c}$ values indicate convergent (divergent) curvature.

The remainder of this paper will focus on the organization of contour curvature within hillslopes and catchments.

\section{Hillslope analysis}

The hsB hydrological model is designed for the hillslope scale; catchment response is to be modelled by tying together many hillslopes with a channel routing function, such as described by Troch et al. (1994). Hillslope morphological parameters of the hsB model are hillslope length $L$, mean hillslope gradient $\alpha$, and the semi-distributed hillslope width function $w(x)$.

So far, the hsB model has mainly be applied to theoretical cases using highly idealized hillslope geometries, spanning the whole range of profile and contour curvatures.

However, delineating a catchment into individual hillslopes, that each fall in the classes convergent, divergent and parallel, is a nontrivial problem. The main reason for this is that the lateral boundaries of a hillslope are in principle undefined. Measuring along a contour line, contour curvature continuously changes.

A much more practical way of delineating hillslopes, also suggested by Fan and Bras (1998), is to distinguish between "headwaters" and "sideslopes". Headwaters being those zero-order basins that drain directly towards a channel head. Sideslopes are those hillslopes that drain directly towards a channel link. Generally speaking, headwaters will be mainly convergent in nature, and sideslopes parallel and divergent.

Figure 2 shows for the Plynlimon catchments in Wales (e.g. Brandt et al., 2004) the probability densities of contour curvature for all $15 \mathrm{~m}$ DEM grid cells that belong to the headwater or sideslope classes. The channel network was defined 


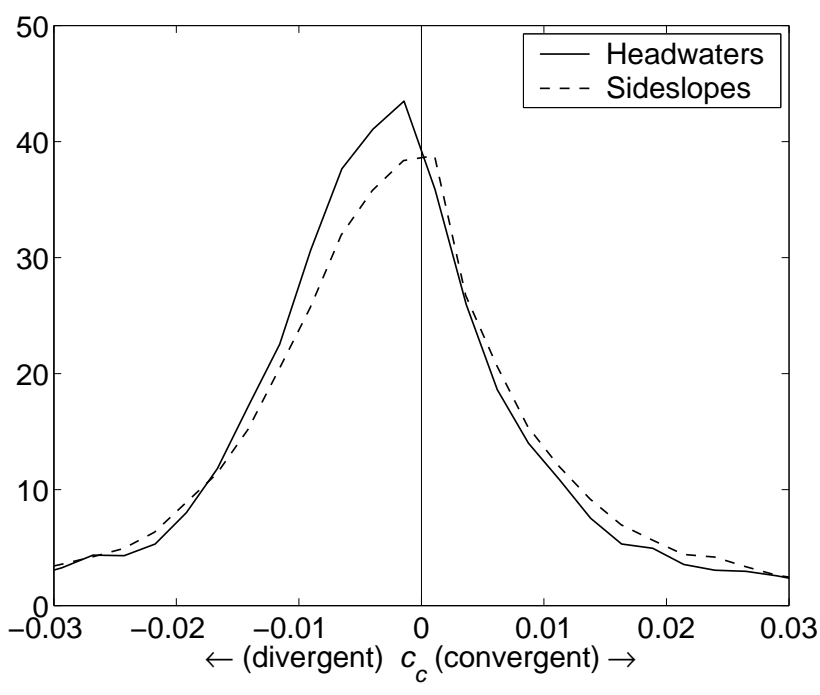

Fig. 2. Probability density of contour curvature, $c_{c}$ for headwater and sideslope DEM grid cells, for the Plynlimon catchments, Wales

as all DEM grid cells having a contributing area of at least $10000 \mathrm{~m}^{3}$, roughly consistent with maps and a slope-area analysis (see Fig. 7). Note that both slope types are dominantly divergent, and that headwaters appear to be even more divergent than sideslopes, which is counterintuitive. Median values for contour curvature are $c_{c}=-2.6 \times 10^{-3} \mathrm{~m}^{-1}$ for headwaters and $c_{c}=-1.7 \times 10^{-3} \mathrm{~m}^{-1}$ for sideslopes. The fact that the $c_{c}$ distribution appears to be skewed towards divergence is in contrast with the prior estimation that catchments should be overall convergent, because they can be regarded as an area draining towards a single point (i.e. the catchment outlet). This is discussed in greater detail in Sect. 5, below.

The relative abundance of convergent grid cells within sideslopes is caused by the large variability of curvature within a single hillslope. To a large extent, this variability is due to hollows. The nature of these hollows will be discussed below.

The hillslope width function $w(x)$ is essentially the distribution of downstream path lengths. Every grid cell can be though of being the origin of a flow path that follows a steepest descent (as the water flows) path towards the channel network, where it terminates.

The obvious way to compute flowpath length for each hillslope grid cell is to trace a single-flow-direction path. In this method, flow originating from cell $c$ is passed to that neighbour cell $n$ out of 8 , that has the steepest downhill gradient between $c$ and $n$. This is similar to the classic "D8" algorithm for computing upstream contributing area (O'Callaghan and Mark, 1984). McGuire et al. (2005) uses path lengths computed in this way to explain inter-catchment mean residence time variability.

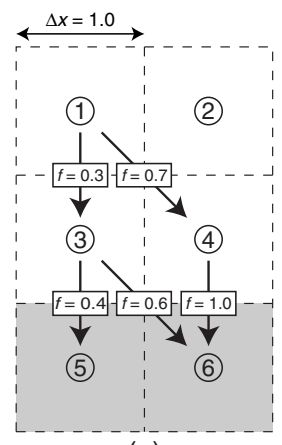

(a)

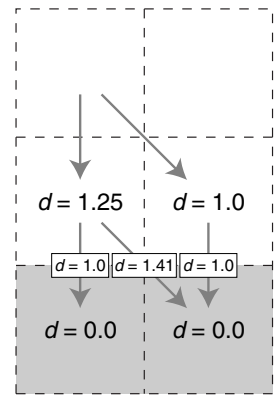

(b)

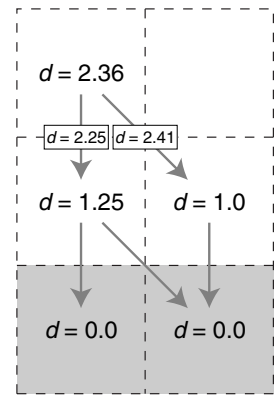

(c)
Fig. 3. Illustration of the multidirectional flow distance algorithm. (a): flow fractions $f$ from every cell to at most 2 lower neighbours. (b): First step of $d(c)$ computations. The small-print boxed number on top of the arrows indicate path lengths along that route. The large unboxed numbers in the cell center indicate computed $d(c)$ values. (c): Second and last step.

However, it is widely acknowledged that the D8 algorithm does a poor job when applied to divergent landscapes. Flow on divergent hillslopes does not diverge; it keeps flowing on a single flow path, while other paths may join. In essence, the D8 algorithm is convergent by design. To solve this problem (for computing contributing area) several multidirectional flow redistribution algorithms have been proposed, among which those by Quinn et al. $(1991,1995)$ and Tarboton (1997) are the most widely applied. These models do not have the constraint that water originating from a grid cell $c$ is passed to a single neighbour $n$. Instead, water is passed to 2 (Tarboton, 1997) or all lower neighbours (Quinn et al., 1991, 1995). In this way, flow on divergent topographies will be divergent as well.

The higher predictive quality of these multidirectional flow redistribution methods (Schmidt and Persson, 2003; Güntner et al., 2004; Pan et al., 2004; Erskine et al., 2006) raise the question whether there are any advantages for computing flow distances too. Here we present a flow-path length algorithm that takes divergent flow into account.

One property of multidirectional flow path algorithms is that unique flow paths do not exist. Therefore, flow distance between a grid cell $c$ is not defined by a single number, but by a distribution of distances instead, see also Fig. 3. Unfortunately, the determination of this full distribution is computationally extremely demanding for the general case of flow distribution among all lower neighbours, because all possible paths between every grid cell and the channel network has to be considered, which is an $O\left(N^{2}\right)$ problem.

The practical solution adopted here is to trace the first moment of this distribution only. the following pseudo code describes the algorithm:

1. Sort all cells $c$ by $z$.

2. Set $d(c)=0$ for all $c$ that are in the channel network. 

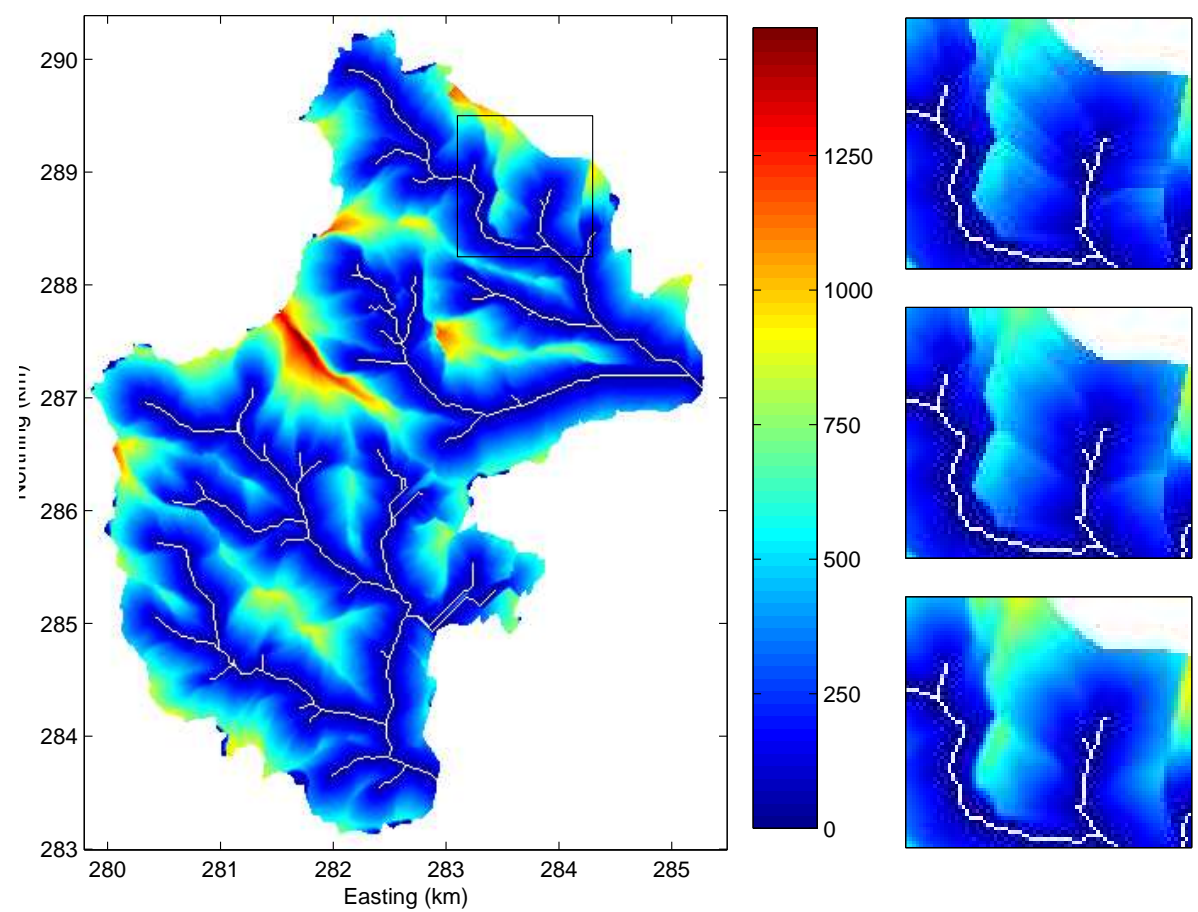

$-500$

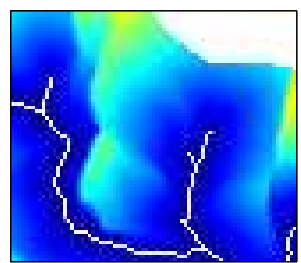

Fig. 4. Flow distance field for the Plynlimon catchments. Left: Flow distance as computed using the Quinn et al. (1991) multiple flow direction method ("MFR-Q"). Right, top: detail showing the D8 single-flow direction method ("SFD”). Right, middle: detail showing the Tarboton (1997) multidirectional flow redistribution method ("MFR-T"). Right, bottom: detail showing the MFR-Q method.

3. Let $\Delta_{i}$ be the inter-cell distances in all 8 directions $i$.

4. For each hillslope cell $c$ :

5. For each direction $i$ :

6. Compute flow fraction $f_{i}$ towards neighbour $n_{i}$ of $c$.

7. end for.

8. For all directions $i$ where $f_{i} \neq 0$ :

9. Compute the flow distance along a path through neighbour $n_{i}$ as $d_{i}=d\left(n_{i}\right)+\Delta_{i}$.

10. end for.

11. Compute $d(c)$ as the weighted mean of flow distances along all paths $i$ as $d(c)=\sum f_{i} d_{i}$.

12. end for.

Notes: a.d. 1.: $d_{c}$ depends on $d_{n}$, where $n$ are those neighbours of $c$ that are connected to $c$ by flow paths. All $n$ are guaranteed to be lower than $c$ in all optional flow partitioning schemes. By iterating through the DEM from lowest to highest cells, it is thus guaranteed for all $c$ that when $d(c)$ is to be computed, all $d(n)$ are known. In this way, recursion code, and associated computational inefficiencies, can be avoided, though the algorithm itself is defined recursively. a.d. 2.: The lowest hillslope grid cells have some $n$ that are channel grid cells. Setting $d=0$ for these channel cells avoids having to take the lowest hillslope cells as a special case.

a.d. 5.: These flow fractions are to be computed according to the schemes proposed by Quinn et al. $(1991,1995)$ Tarboton (1997) or any other multidirectional flow redistribution algorithm. Note that single flow direction algorithms such as the classic D8 method can also be used here. In that case only one $f_{i}$ is set to 1 , and all other $f_{i}$ are 0 .

Figure 3 illustrates the algorithm. Flow originating in cell 1 has three different ways to end up in the channel network, by path $1 \rightarrow 3 \rightarrow 5$, by path $1 \rightarrow 3 \rightarrow 6$, and by path $1 \rightarrow 4 \rightarrow 6$. A complete analysis would involve and averaging all these path lengths to obtain $d(1)$ as a distribution of lengths. Our (recursive) algorithm defines $d(1)$ in terms of $d(3), d(4), f_{1 \rightarrow 3}$ and $f_{1 \rightarrow 4}$.

Figure 4 shows a map of flow distance, for the Plynlimon catchments, Wales (e.g. Brandt et al., 2004). Insets show how the flow distance field vary with the method chosen.

\section{Width functions}

Flow distance fields are useful to parameterize the hsB model. The required hillslope width function $w(x)$ is equivalent with the frequency of flow distances. Figure 5 shows 
the histograms of flow distances, as shown in Fig. 4, and as computed by three different flow distance algorithms.

It can be seen from this figure that the shape of the $w(x)$ function is clearly influenced by the flow redistribution method used, especially for the headwater hillslopes. The general trend observed is that MFR methods skew the distribution towards higher distances; slightly for the MFR-T method, much stronger for the MFR-Q method. This can be explained by the divergence that is inherent in the MFR methods in general and the MFR-Q method in particular. Because flow dispersion is taken into account, multiple flow paths connect each grid cell with the channel network. The steepest-descent path is likely to correspond to the shortest path, but the alternative paths are longer. Because MFR-Q includes more dispersion than MFR-T, even longer paths are included, although with a small weight. Median flow path lengths for the headwater hillslopes are 5\% (MFR-T) and $27 \%$ (MFR-Q) higher than for SFD path lengths. For the sideslopes these numbers are slightly smaller, $1.5 \%$ and $20 \%$, respectively. For all hillslopes taken together the effect is $2.5 \%$ and $22.5 \%$.

The general shape of the width functions, as shown in Fig. 5 requires some attention. The width function for headwaters are first increasing, and then decreasing. This can be explained by the way that headwater hillslopes are placed within the landscape. Headwaters are thought to capture much of the convergent parts of the catchment, because they form areas where flow converges towards a single point: the channel head. Hillslope width on this point $(x=0)$ is very small (theoretically it could be zero). Then, the hillslope is becoming wider, so $w(x)$ is increasing. The upper boundary of hillslopes are formed by (local) divides. This divide is generally not on equal distance from the channel, nor does it have a uniform elevation. Usually the divide is a ridgelike feature consisting of hilltops and saddles. The lowest saddle of this divide also defines the highest continuous topographic contour line. Above this line, the hillslope is no longer necessarily continuous but may consists of multiple parts. This is reflected in the width function turning into a decreasing $w(x)$ function, reflecting the divergent nature of the hillslope fragments in these locations (the hilltops on the divide). Note, however, that the highest continuous contour is not necessarily the location of the modal flow distance. Finally, there is only a single location (usually a hilltop) that is at the maximum flow distance from the channel network. Therefore, $w(x)$ should be decreasing toward $w=0$ at $x=L$, where $L$ is the length of the hillslope.

Sideslopes, on the contrary are more characterized by divergent and parallel hillslope fragments. This is reflected by the $w(x)$ functions that are almost strictly decreasing. Only for the very low $x$ range $w(x)$ seems to be slightly increasing. This effect is absent for the SFD algorithms, and strongest for the MFR-Q algorithm. This suggests that it is caused by riparian area dispersion. Because in these areas topographic slopes are relatively small, and valley bottoms wide, flow

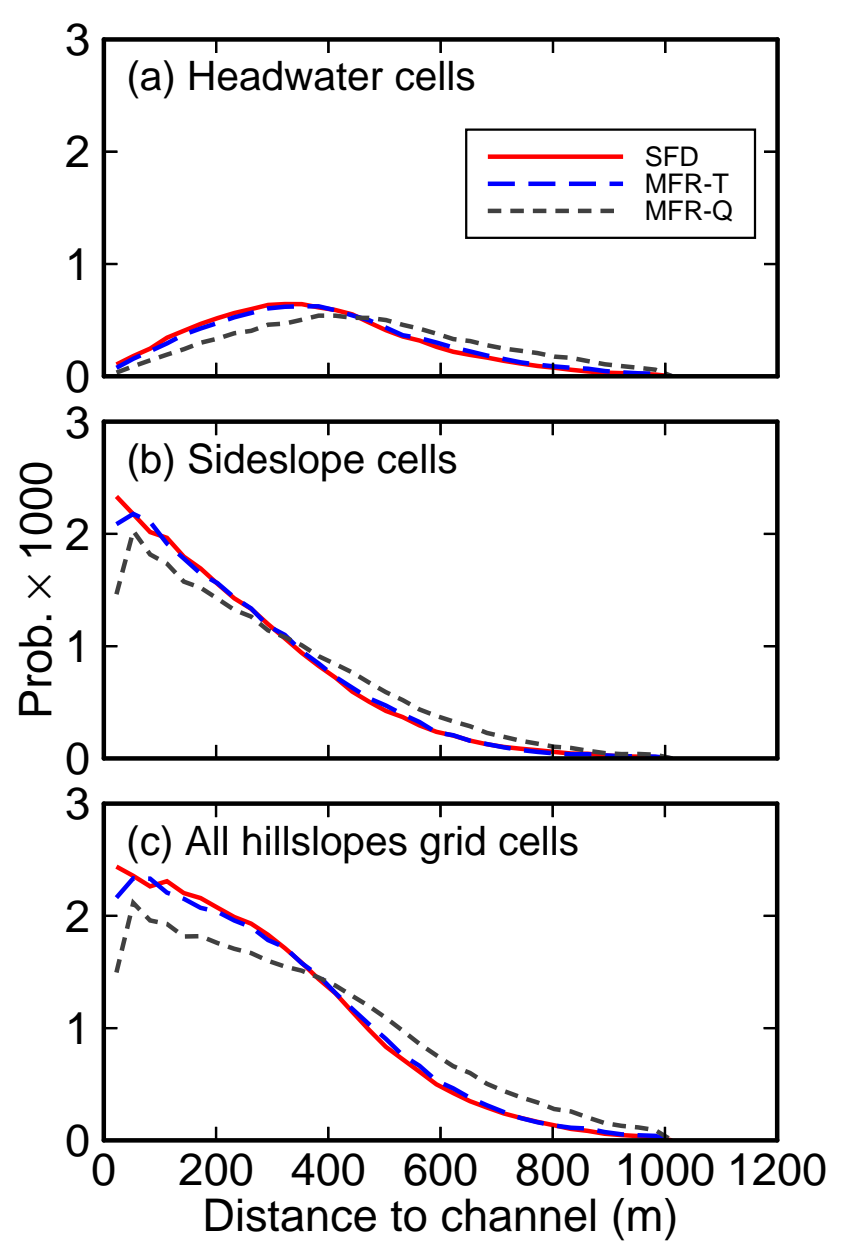

Fig. 5. Flow distance probability densities for headwater hillslope grid cell, sideslope hillslope grid cells, and combined. Methods used are using the D8 SFD algorithm, the Quinn et al. (1991) MFR algorithm (MFR-Q), and the Tarboton (1997) MFR algorithm (MFR-T). Probability densities are calculated such that the total probabilities for the headwaters and sideslopes sum up to that of all hillslopes, which is 1 .

paths tend to diverge here. Near-channel grid cells thus cannot be expected to take the shortest route to the channel network, but instead have some fraction of flow that moves parallel to the streams for some while before joining the channel. Therefore, very short cell-to-channel distances are less likely, and hence their frequency is lower.

Also shown in Fig. 5 is the overall width function when all hillslope grid cells are taken together. This overall width function is the sum of the headwater and sideslope width functions. What is most striking about the shape of the overall width function is that it is mainly decreasing. This is caused by the much larger area of sideslope cells compared to headwater cells. therefore the contribution of the convergent lower part of the headwater width function to the overall width function is rather small, and not strong enough to prevent decreasing $w(x)$ for $d>30 \mathrm{~m}$. 
Table 1. Curvature statistics for various subsets of the Plynlimon catchments DEM grid cells. subsets are: hillslope grid cells $(\mathrm{H})$, sideslope hillslope grid cells (S), both slope types (HS), and any grid cell (HSC).

\begin{tabular}{lrr}
\hline class & mean $c_{c}$ & median $c_{c}$ \\
\hline H & 0.2432 & -0.0026 \\
S & -0.0874 & -0.0018 \\
HS & 0.0079 & -0.0020 \\
HSC & 0.0102 & -0.0020 \\
\hline
\end{tabular}

\section{The convergence paradox}

The overall width function as shown in Fig. 5 (c) is clearly decreasing. This suggest that the catchment as a whole is dominated by divergence. This is in sharp contrast to what is to be expected. Because the catchment can be regarded as an area that drains towards a single point (the outlet) it should be convergent in overall shape.

As described above, Delineating a catchment in headwater and sideslopes, and using the width functions of these as indicators of convergence and divergence is just a practical approach. A more fundamental convergence/divergence analysis should be based on per-cell contour curvature and the statistics thereof.

Table 1 lists, for the Plynlimon catchments, the mean and median contour curvature $c_{c}$ for all grid cells that belong to a headwater hillslope (subset "H"), a sideslope hillslope (subset "S"), any hillslope (subset "HS"), or any cell within the drainage basin, including those grid cells that form the channel network (subset "HSC").

It can be seen from the mean curvature data that indeed headwater hillslopes are convergent on average (mean $c_{c}>0$ ), and sideslopes are divergent (mean $c_{c}<0$ ). The HS and HSC subsets also are convergent on average. This confirms the expectations, i.e. that the catchment as a whole should be convergent. However, when inspecting the median curvatures for all 4 subsets, one sees that these are all negative. Thus, in 3 of the 4 subsets mean $c_{c}>0$ while median $c_{c}<0$. These opposite signs suggest that the curvature distributions are significantly skewed, or that extreme values play an important role.

To investigate the effect of skewness and extremes in the curvature distribution, the distribution has been cutoff at a range of percentile values. This is shown in Fig. 6. It can be seen that the average of (say) the 1st and 99th percentile is positive. This indicates that extreme values are dominated by $c_{c}>0$. This behaviour is up to (approximately) the 10th and 90th percentile. From the average of 20th and 80th percentiles onward, the value is negative, and coincides with the overall median curvature. This indicates that for this range, the curvature distribution is skewed towards divergence, and the effect of extreme values is absent.

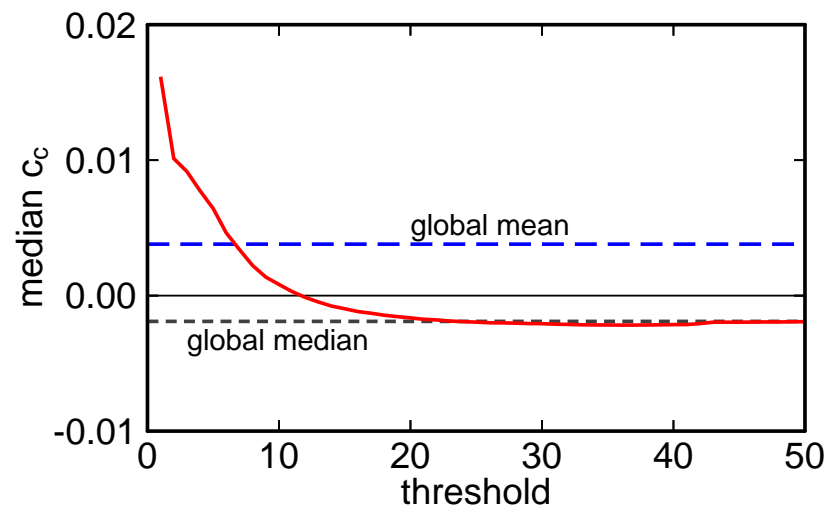

Fig. 6. Diagram illustrating the asymmetric tails of contour curvature distribution. For every threshold $i$ the $i$ th and the $(100-i)$ th percentiles have been computed. The red solid line indicates the average of these two percentiles. The dashed lines indicate the global mean curvature $(>0$; convergent) and global median curvature $(<0$; divergent).

A preliminary conclusion, therefore, is that the "curvature paradox" is caused by the fact that the majority of grid cells is divergent, but the catchment-scale curvature is still convergent, because of a small fraction of grid cells that are strongly convergent.

Additional information can be obtained from Table 1. The median values for all-hillslope and all-basin grid cells are equal, while the mean values are not. This by itself indicates the effect of extreme values, for which the mean is sensitive while the median isn't. The difference between the two classes considered is that HSC includes channel grid cells, while HS doesn't. Therefore, the extreme convergent grid cells should be located in the channel grid cells, which does make sense.

This hypothesis can be tested in a systematic way by plotting contour curvature against contributing area, see Fig. 7. This graph shows a strong curvature-area relationship. For small contributing area $\left(A<1500 \mathrm{~m}^{2}\right)$ curvature is dominantly divergent $($ median $<0)$. For large areas $\left(A>5000 \mathrm{~m}^{2}\right)$ curvature is dominantly convergent (10th percentile $>0$ ). The intermediate range of $1500<A<5000 \mathrm{~m}^{2}$ is a transition zone in which the median curvature is $>0$, but the 10th percentile is $<0$.

These zones can be interpreted in terms of dominant geomorphological processes, based on the signature that these processes create in slope-area plots (Tarboton et al., 1991; Ijjász-Vásquez and Bras, 1995; Tucker and Bras, 1998). Such a plot has been included in Fig. 7. Three zones can be distinguished. Zone I $\left(A<1500 \mathrm{~m}^{2}\right)$ is interpreted as hillslopes where diffusional sediment transport dominates. Zone II $\left(1500<A<5000 \mathrm{~m}^{2}\right)$ is interpreted as hillslope hollows where episodic transport in the form of debris flow and/or shallow landsliding dominates. These hollows are to a large extent responsible for the large variability of contour curva- 


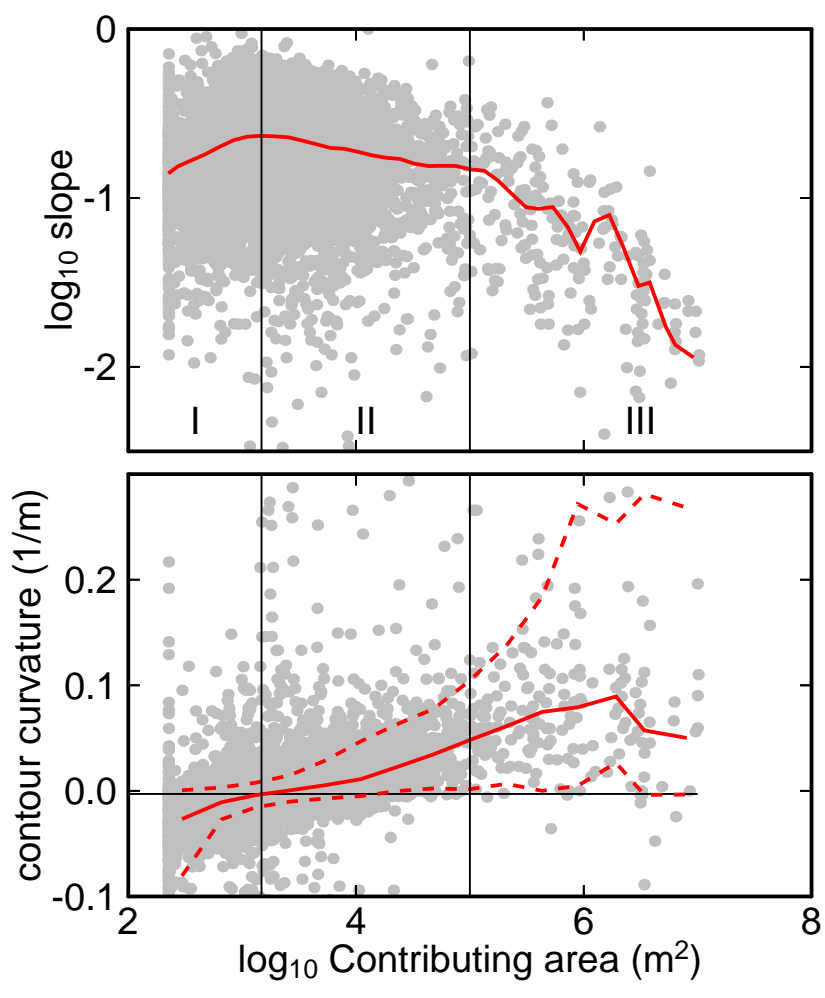

Fig. 7. Top: Slope $\alpha$ vs contributing area $A$ for the Plynlimon catchments. Dots are individual grid cells. The red solid line represents the mean $S$ for small bins of $A$. The indicated regions are: I: diffusion dominated hillslopes; II: hillslope hollows sensu Stock and Dietrich (2003); III: channels. Bottom: Contour curvature $c_{c}$ vs contributing area. Dots are individual grid cells. The red solid line indicates the median $c_{c}$ for small bins of $A$. The dashed red lines indicate the 10th and 90th percentile of $c_{c}$.

ture within hillslopes. Zone III $\left(A>5000 \mathrm{~m}^{2}\right)$ is interpreted as the semi-permanent channel network, where "fluvial" sediment transport is most dominant.

These zones and processes can be related to the corresponding contour curvature. Grid cells in zone I are part of diffusional hillslopes that have a characteristic dome-like shape. As a result, profile curvature is convex, and contour curvature is divergent. Grid cells in zone II are often part of hillslope hollows. Contour curvature is either zero or lightly positive. Grid cells in zone III are part of the channel network, forming valleys in between hillslopes. As a result, contour lines that cross the channels have a strong positive (convergent) curvature.

\section{Curvature effects on hydrological response}

Convergence and divergence form a first-order topographic control on the hydrological response of hillslopes and catchments. This is recognized in many conceptual hillslope hydrological models. In the TOPMODEL (Beven and Kirkby,

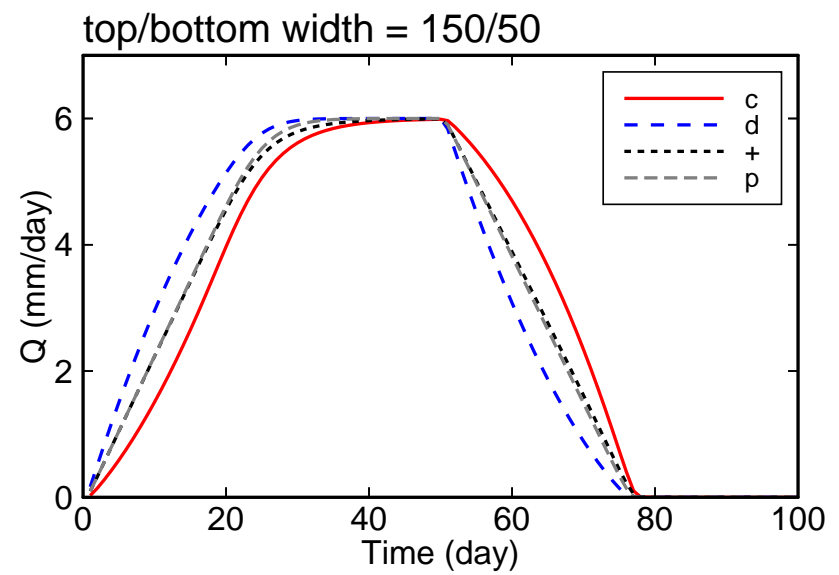

Fig. 8. Hydrological response for hillslopes with top/bottom widths of 50 and $150 \mathrm{~m}$ (case I): "c" marks the response of the convergent hillslope; "d" marks the response of the divergent hillslope; "+" marks the response of both hillslopes combined; "p" marks the response of the $200 \mathrm{~m}$ wide parallel hillslope with equal width as the convergent and divergent one combined.

1979; Beven, 1997), convergence is one of the parameters that define the value of the topographic index of a grid cell. In the hillslope-storage Boussinesq model (Troch et al., 2003), convergence/divergence are parameterized by the hillslope width function, $w(x)$.

A full discussion of the hydrological consequences of curvature organization within catchments is beyond the scope of the present paper but we will present one example here. It has been mentioned above that there is a wide variability of grid cell scale contour curvature within individual headwater or sideslope hillslopes. Therefore, one can question what the effect is of lumping convergent and divergent areas within a single computational hillslope.

A simple conceptual numerical experiment has been set up: Consider a hillslope that is $200 \mathrm{~m}$ long and $200 \mathrm{~m}$ wide. Such a hillslope can be considered to be neither convergent nor divergent, but parallel. In this case, the width function is uniform $(w(x)=200$ for all $x)$. For a given forcing, this hillslope gives a certain hydrological response in terms of $Q(t)$, where $Q$ is discharge.

Now, this hillslope can be sliced into two halves. If these halves are both $100 \mathrm{~m}$ wide, they can be considered to be parallel as well. The response of these sub-hillslopes equals that of the large hillslope, when added. This is a property of the width-functions to be uniform. What happens when the two halves are not parallel is less clear. We test two cases. In case $\mathrm{I}$, the first half-hillslope will be $50 \mathrm{~m}$ wide at the bottom, and $150 \mathrm{~m}$ wide at the top. This creates a convergent hillslope. The other hillslope is $150 \mathrm{~m}$ wide at the bottom and $50 \mathrm{~m}$ wide at the top, creating a divergent hillslope. Note that total area is preserved with this setup. In case II, these widths are 20 and 180, respectively. Other model parameters are: slope 
top/bottom width $=180 / 20$

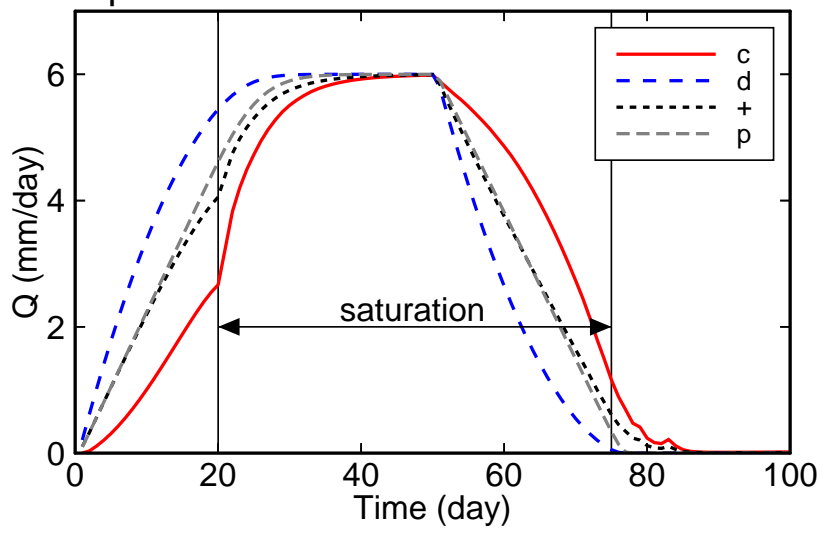

Fig. 9. Hydrological response for hillslopes with top/bottom widths of 20 and $180 \mathrm{~m}$ (case II). Legends as for Fig. 8. The arrow marks the period during which saturation was obtained at the foot of the convergent hillslope.

gradient $\alpha=0.10$, drainable porosity $f=0.3$, saturated hydraulic conductivity $k=1.0 \mathrm{~m} \mathrm{hr}^{-1}$, soil depth $D=2 \mathrm{~m}$. Initial conditions are a dry soil. Forcing is such that steady state will be reached: recharge rate $N=6 \mathrm{~mm} \mathrm{~d}^{-1}$ during $50 \mathrm{~d}$, followed by an equal period of free drainage.

Results are shown in Figs. 8 and 9. The responses for the convergent and divergent hillslopes are plotted. Discharge during the recharge phase is lower for the convergent hillslope than for the divergent hillslope. This is caused by a higher dynamic storage capacity within the convergent hillslope because water tables will rise higher. This effect is reversed during the drainage phase: discharge from the convergent hillslope is higher because of the larger water reservoir that has been build up during steady state. The effect is quite strong: discharge from the convergent hillslope is twice that of the divergent hillslope around time $70 \mathrm{~d}$. Also plotted are the average response of the convergent and divergent hillslope combined, and the response of an equivalent parallel hillslope. These two discharge responses are almost equal, suggesting that while convergence/divergence is an important control on individual hillslope response, within-hillslope variability of convergence and divergence can be ignored.

Figure 9 shows the results of the second case, where the degrees of convergence and divergence are much stronger. The shape of the individual hillslope responses is different in character than in Fig. 8, especially the response of the convergent hillslope. This is due to saturation at the downward end of the hillslope. As a result, saturation excess overland flow is generated, causing the sudden rise in discharge after time $20 \mathrm{~d}$. Again the responses of the combined and equivalent parallel hillslopes are plotted. Now there is a larger deviation between these two discharge responses. However, the differences are still relatively small, especially for the drainage part of the experiment.

\section{Discussion and conclusions}

A new algorithm has been presented to compute flowpath lengths from hillslope grid cells towards the channel network. This algorithm is able to take flow path divergence into account, by allowing multidirectional flow redistribution every grid cell. The algorithm has been tested by comparing path length fields for three different methods to describe per-cell flow redistribution, using the classic D8 single-flowdirection scheme (SFD), and the Quinn et al. (1991) and Tarboton (1997) redistribution schemes (MFR-Q and MFR-T, respectively). It was found that SFD and MFR gave comparable results, while MFR-Q resulted in a significant higher $(\approx 20 \%)$ median path length when averaged over the whole catchment. These and other characteristics could be explained from the response of the methods to hillslope, and riparian area morphology, considering the variable degree of dispersion in all three methods.

A so-called curvature paradox has been identified. Catchment-scale hillslope width functions suggest that catchments are divergent in overall shape, which is in contrast to the intuitive perception that catchments should be overall convergent because they are essentially an area draining towards a single point (the outlet). We have shown how this paradox can be explained by investigating how curvature is organized within the landscape. It has been confirmed that hillslopes are indeed divergent when averaged. However, the drainage network - which is left out of the hillslope width function analysis - contributes the majority of convergence present within catchments. As a result, the overall curvature is indeed convergent when the channel network is considered as well.

It should be noted that topographic convergence/divergence as measured by contour curvature is not equivalent to convergence/divergence as measured by the flow path length distribution. Tentative insights in the relationship between these two measures can be gained from two contrasting, highly idealized isolated hills: a coneshaped and a pyramid-shaped hill. For both hills, it is clear that the path length distribution will be "divergent". However, a contour curvature analysis will result in "divergent" for the cone-shaped hill, and "parallel" (neither convergent nor divergent) for the pyramid-shaped hill, because of the clearly planar hillslopes. The cone shaped hill should represent a (geomorphic) diffusion dominated landscape (although the characteristic hill shape then would be a dome, rather than a cone - but that does not alter the conclusions drawn here), having a moderate slope gradients, and the pyramid shaped hill should represent a steep landscape, where land slides are the dominant geomorphic process. The catchment discussed here, Plynlimon, is assumed to belong to the "cone/dome" geomorphic class rather than to the "pyramid" class. However, a full discussion of the relation relation between the two convergence measured would require a study comparing a range of catchment mor- 
phologies, and associated dominant geomorphic processes, and is beyond the scope of this paper.

It should be noted too, that a number of simplifying assumptions have been made in the current analysis:

- The catchment is considered to be "small", such that the response time is dominated by hillslope delays. In "large" catchments, stream flow delays will become significant. Also, most headwaters can be expected to be located remote with respect to the catchment outlet. The average channel routing delay from headwaters thus can be expected to be different from the average delay for sideslopes. The effects of this is beyond the scope of the current paper.

- Hydraulic conductivity of the soil layer is considered to be constant with depth. In reality, conductivity will most often decrease with depth. This will likely affect the behaviour of convergent and divergent hillslopes, especially for the recession behaviour. Again, this effect is beyond the scope of the current paper.

We have presented a simple numerical experiment to test to what extent within-hillslope curvature variability affects the hydrological response of hillslopes. It has been found that the effects of convergent and divergent areas on the total hydrograph almost cancels out, making the total intra-hillslope curvature variability effect small. This is even the case when a saturation threshold has been exceeded.

This effect can also be scaled up from the hillslope to the catchment scale (from intra-hillslope curvature variability to inter-hillslope curvature variability) without loss of generality. Based on our findings, convergent hillslopes do compensate for equivalent but divergent hillslopes. Only the total net amount of convergence would define the nature of the catchment response. These findings may assist in creating efficient catchment-scale hydrological models, because it does provide justification for the clustering together, without sacrificing precision, of individual convergent and divergent hillslopes into a single hillslope width function, as applied by Troch et al. (1994) to a catchment in the Appalachian mountains.

In summary, these results provide some justification for the view that a whole landscape could be regarded as one single large hillslope folded around the channel network. The analysis presented in this paper showed that this hillslope is a divergent one.

Acknowledgements. This research is funded by WIMEK (Wageningen Institute for Environmental and Climate Studies) project 410-39809 and NWO (Netherlands Scientific Research) project 857.00.008. Mark Robinson of the Centre for Ecology and Hydrology (Wallingford, UK) is kindly acknowledged for providing the digital elevation data for Plynlimon. The data itself was derived from a topographic survey commissioned by the NERC (British Natural Environment Research Council).

Edited by: E. Zehe

\section{References}

Aryal, S. K., OLoughlin, E. M., and Mein, R. G.: A Similarity approach to predict landscape saturation in catchments, Water Resour. Res., 38, 1208, doi:10.1029/2001WR000864, 2002.

Aryal, S. K., O’Loughlin, E. M., and Mein, R. G.: A similarity approach to determine response times to steady-state saturation in landscapes, Adv. Water Resour., 28, 99-115, 2005.

Berne, A., Uijlenhoet, R., and Troch, P. A.: Similarity analysis of subsurface flow response of hillslopes with complex geometry, Water Resour. Res., 41, W09410, doi:10.1029/2004WR003629, 2005.

Beven, K.: TOPMODEL: A critique, Hydrol. Process., 11, 10691085, 1997.

Beven, K. J. and Kirkby, M. J.: A physically based, variable contributing area model of basin hydrology, Hydrol. Sci. B., 24, 4369, 1979.

Brandt, C., Robinson, M., and Finch, J. W.: Anatomy of a catchment: the relation of physical attributes of the Plynlimon catchments to variations in hydrology and water status, Hydrol. Earth Syst. Sci., 8, 345-354, 2004.

Canfield, H. E. and Goodrich, D. C.: The impact of parameter lumping and geometric simplification in modelling runoff and erosion in the shrublands of southeast Arizona, Hydrol. Process., 20, 17 35, doi:10.1002/hyp.5896, 2006.

Erskine, R. H. T. R. G., Ramirez, J. A., and MacDonald, L. H.: Comparison of grid-based algorithms for computing upslope contributing area, Water Resour. Res., 42, W09416, doi:10.1029/2005WR004648, 2006.

Fan, Y. and Bras, R. L.: Analytical solutions to hillslope subsurface storm flow and saturation overland flow, Water Resour. Res., 34, 921-927, 1998.

Güntner, A., Seibert, J., and Uhlenbrook, S.: Modeling spatial patterns of saturated areas: An evaluation of different terrain indices, Water Resour. Res., 40, W05114, doi:10.1029/2003WR002864, 2004.

Ijjász-Vásquez, E. J. and Bras, R. L.: Scaling regimes of local slope versus contributing area in digital elevation models, Geomorphology, 12, 299-311, 1995.

Kirkby, M. J.: TOPMODEL: A personal view, Hydrol. Process., 11, 1087-1097, 1997.

Martin, Y.: Modelling hillslope evolution: linear and nonlinear transport relations, Geomorphology, 34, 1-21, 2000.

McGuire, K. J., McDonnell, J. J., Weiler, M., Kendall, C., McGlynn, B. L., Welker, J. M., and Seibert, J.: The role of topography on catchment-scale water residence time, Water Resour. Res., 41, W05002, doi:10.1029/2004WR003657, 2005.

Mitasova, H. and Hoffierka, J.: Interpolation by regularized spline with tension: II. Application to terrain modelling and surface geometry analysis, Math. Geol., 25, 657-669, 1993.

O'Callaghan, J. F. and Mark, D. M.: The extractionof drainage networks from digital elevation data, Comput. Vision Graphics Image Process., 28, 328-344, 1984.

O'Loughlin, E. M.: Prediction of Surface Saturation Zones in Natural Catchments by Topographic Analysis, Water Resour. Res., 22, 794-804, 1986.

Pan, F., Peters-Lidard, C. D., Sale, M. J., and King, A. W.: A comparison of geographical information systemsbased algorithms for computing the TOPMODEL topographic index, Water Resour. Res., 40, W06303, doi:10.1029/2004WR003069, 2004. 
Quinn, P., Beven, K., Chevallier, P., and Planchon, O.: The prediction of hillslope flow paths for distributed hydrological modelling using digital terrain models, Hydrol. Process., 5, 59-79, 1991.

Quinn, P. F., Beven, K. J., and Lamb, R.: The $\ln (a / \tan \beta)$ index: how to calculate it and how to use it within the TOPMODEL framework, Hydrol. Process., 9, 161-182, 1995.

Roering, J. J., Kirchner, J. W., and Dietrich, W. E.: Evidence for nonlinear, diffusive sediment transport on hillslopes and implications for landscape morphology, Water Resour. Res., 35, 853870, 1999.

Rosenbloom, N. A. and Anderson, R. S.: Hillslope and channel evolution in a marine terraced landscape, Santa Cruz, California, J. Geophys. Res., 99B, 14 013-14 029, 1994.

Schmidt, F. and Persson, A.: Comparison of DEM data capture and topographic wetness indices, Precis. Agric., 4, 179-192, 2003.

Schmidt, J., Evans, I. S., and Brinkmann, J.: Comparison of polynomial models for land surface curvature calculation, Int. J. Geogr. Inf. Sci., 17, 797-814, 2003.

Sivapalan, M., Wood, E. F., and Beven, K. J.: On Hydrologic Similarity 3. A Dimensionless Flood Frequency Model Using a Generalized Geomorphologic Unit Hydrograph and Partial Area Runoff Generation, Water Resour. Res., 26, 43-58, 1990.

Smith, R. E., Goodrich, D. C., Woolhiser, D. A., and Unkrich, C. L.: KINEROS - a kinematic runoff and erosion model, in: Computer Models of Watershed Hydrology, edited by: Singh, V. J., Water Resour. Publ., pp. 697-732, 1995.

Smith, T. R. and Bretherton, F. P.: Stability and the Conservation of Mass in Drainage Basin Evolution, Water Resour. Res., 8, 15061529, 1972.

Smith, T. R., Birnir, B., and Merchant, G. E.: Towards an elementary theory of drainage basin evolution: I. The theoretical basis, Comput. Geosci., 23, 811-822, doi:10.1016/S00983004(97)00068-X, 1997.
Stock, J. and Dietrich, W. E.: Valley incision by debris flows: Evidence of a topographic signature, Water Resour. Res., 39, 1089, doi:10.1029/2001WR001057, 2003.

Tarboton, D. G.: A new method for the determination of flow directions and upslope areas in grid digital elevation models, Water Resour. Res., 33, 309-319, 1997.

Tarboton, D. G., Bras, R. L., and Rodriguez-Iturbe, I.: On the extraction of channel networks from digital elevation data, Hydrol Process., 5, 81-100, 1991.

Tarboton, D. G., Bras, R. L., and Rodriguez-Iturbe, I.: A physical basis for drainage density, Geomorphology, 5, 59-76, 1992.

Troch, P., van Loon, E., and Hilberts, A.: Analytical solutions to a hillslope-storage kinematic wave equation for subsurface flow, Adv. Water Resour., 25, 637-649, 2002.

Troch, P. A., Smith, J. A., Wood, E. F., and de Troch, F. P.: Hydrologic controls of large floods in a small basin: central Appalachian case study, J. Hydrol., 156, 285-309, 1994.

Troch, P. A., Paniconi, C., and van Loon, E. E.: Hillslopestorage Boussinesq model for subsurface flow and variable source areas along complex hillslopes: 1. Formulation and characteristic response, Water Resour. Res., 39, 1316, doi:10.1029/2002WR001728, 2003.

Tucker, G. E. and Bras, R. L.: Hillslope processes, drainage density, and landscape morphology, Water Resour. Res., 34, 2751-2764, 1998.

Woolhiser, D., Smith, R., and Goodrich, D. C.: A kinematic runoff and erosion model: documentation and user manual, Report 77, Agricultural Research Service, United States Department of Agriculture, 1990. 